\title{
VALIDAÇÃO DE MÉTODO POR CROMATOGRAFIA LÍQUIDA DE ALTA EFICIÊNCIA PARA DETERMINAÇÃO DA LAMIVUDINA E ZIDOVUDINA EM COMPRIMIDOS
}

Ruy Carlos Ruver Beck*, Simone Gonçalves Cardoso, Margareth Linde Athayde, Cristiane Codevilla, Fernanda Kreutz de Oliveira e Sérgio Luiz Dalmora

Departamento de Farmácia Industrial, Centro de Ciências de Saúde, Universidade Federal de Santa Maria, Prédio 26, 97105-900 Santa Maria - RS, Brasil

Recebido em 8/8/06; aceito em 9/11/06; publicado na web em 2/7/07

VALIDATION OF A HIGH PERFORMANCE LIQUID CHROMATOGRAPHY METHOD FOR THE DETERMINATION OF LAMIVUDINE AND ZIDOVUDINE IN TABLETS. An HPLC method was validated to assay lamivudine and zidovudine combined in tablets. The chromatographic separation was carried out using methanol and acetate buffer $\mathrm{pH} 6.5$ (50:50 v/v) and a RP-18 column, as mobile and stationary phase, respectively. The UV detection was at $270 \mathrm{~nm}$. The method was linear in the range of $24-$ $36 \mu \mathrm{g} / \mathrm{mL}$ (lamivudine) and $48-72 \mu \mathrm{g} / \mathrm{mL}$ (zidovudine). The recovery (accuracy) ranged from $101.35 \%$ to $103.04 \%$ and the precision (repeatability and intermediate precision) was less than $2 \%$. The method can be also applied to the quantification of these drugs in the dissolution test of tablets containing both drugs.

Keywords: HPLC; lamivudine; zidovudine.

\section{INTRODUÇÃO}

Desde a descoberta da Síndrome da Imunodeficiência Adquirida (AIDS) em 1981, tem-se alcançado considerável progresso no desenvolvimento de agentes anti-HIV. Os inibidores da enzima transcriptase reversa, como a lamivudina - 3TC e a zidovudina AZT (Figura 1), foram a primeira classe de fármacos utilizada no tratamento de infecções pelo vírus da imunodeficiência adquirida $\mathrm{HIV}^{1}$. Além da zidovudina ter sido um dos primeiros 2'-3'dideoxinucleosídios a apresentar inibição da transcriptase reversa viral, os estudos clínicos e imunológicos demonstram que a sua introdução no tratamento contribuiu para melhorar e prolongar a vida dos pacientes portadores da $\operatorname{AIDS}^{2,3}$. A lamivudina, que também é um análogo dos dideoxinucleosídios, sofre fosforilação intracelular, dando origem ao metabólito ativo, trifosfato de lamivudina, que assim como a zidovudina age inibindo a atividade da transcriptase reversa. A combinação de fármacos anti-retrovirais é adotada preferencialmente, ao invés da monoterapia, como primeira escolha para tratamento de pacientes com infecções por HIV. A lamivudina administrada em combinação com a zidovudina é um agente efetivo para o tratamento de pacientes tanto sintomáticos, quanto assintomáticos ${ }^{4}$.

O emprego terapêutico e a comercialização da associação da lamivudina e zidovudina estão bem estabelecidos, porém não há

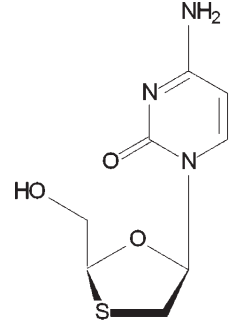

a)

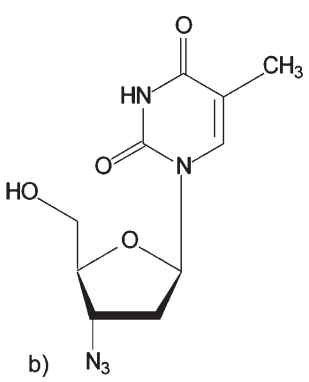

b) $\mathrm{N}_{3}$
Figura 1. Estruturas químicas: a) lamivudina (3TC) e b) zidovudina (AZT)

*e-mail: ruybeck@ smail.ufsm.br monografia oficial para a determinação dessa associação de fármacos em comprimidos ou outras formas farmacêuticas. Uslu e colaboradores $^{5}$ desenvolveram e validaram metodologias para a determinação de ambos os fármacos em comprimidos, por espectrofotometria no ultravioleta e cromatografia líquida. Porém, não sugerem a aplicação do método analítico para a avaliação da percentagem dissolvida (teste de dissolução), além da preparação das amostras requerer a utilização de grande quantidade de solvente orgânico, sendo empregados 100 $\mathrm{mL}$ de metanol para a preparação de cada amostra de comprimidos, com posterior diluição na fase móvel. A literatura descreve ainda métodos por espectrofotometria no $\mathrm{UV}^{6,7}$ e cromatografia líquida ${ }^{1,2,8-11}$ para a determinação destas substâncias em fluídos biológicos de humanos ou animais. Na literatura também podem ser encontrados outros métodos analíticos para a quantificação destes fármacos, porém, isoladamente, em comprimidos, ou em associação com outros fármacos ${ }^{12-20}$. As monografias oficiais para o doseamento de zidovudina e lamivudina, isoladamente em comprimidos, encontram-se descritas na Farmacopéia Brasileira ${ }^{21}$ e na Farmacopéia Americana ${ }^{22}$.

Considerando a carência de métodos descritos na literatura para a quantificação desta associação de fármacos em comprimidos, o objetivo deste estudo foi validar um método através de cromatografia líquida de alta eficiência para a determinação do teor de lamivudina e zidovudina em comprimidos, reduzindo a utilização de solvente orgânico na etapa de preparação das amostras, proporcionando economia e redução do impacto ambiental. O método foi validado de acordo com os seguintes parâmetros: linearidade, faixa de concentração, exatidão, precisão e especificidade. Após a validação foi avaliado o emprego do método desenvolvido na quantificação do teor das substâncias ativas em amostras provenientes do teste de dissolução dos comprimidos.

\section{PARTE EXPERIMENTAL}

\section{Materiais}

As substâncias de referência - lamivudina (3TC) e zidovudina (AZT) - foram gentilmente cedidas pelo Laboratório Cristália (São Paulo, Brasil), apresentando teores de 98,92 e 100,00\%, respecti- 
vamente. Foram utilizadas 6 amostras de comprimidos contendo $150 \mathrm{mg}$ de lamivudina e $300 \mathrm{mg}$ de zidovudina, dentro do seu prazo de validade (amostras A, B, C, D, E e F), obtidas a partir de diferentes laboratórios farmacêuticos. O metanol (grau CLAE), os reagentes e os solventes de grau analítico (acetato de amônia, ácido clorídrico concentrado, hidróxido de amônio e ácido acético glacial) foram utilizados conforme recebidos.

\section{Equipamentos e condições analíticas}

Foi empregado um sistema cromatográfico constituído de duas bombas Shimadzu LC-10AD, detector UV/Vis SPD 10AD e autoinjetor Shimadzu (Shimadzu, Tóquio, Japão). Os cromatogramas foram obtidos e analisados através do programa Class-VP ${ }^{\circledR}$ (Shimadzu, Tóquio, Japão). Como fase estacionária foi empregada uma coluna Lichrospher ${ }^{\circledR} 100$ (RP-18, 250 x 4,6 mm, com partículas de $5 \mu \mathrm{m}$, Merck, Darmstadt, Alemanha) acoplada a uma pré-coluna RP-18 (Merck, Darmstadt, Alemanha). A fase móvel foi constituída pela mistura de metanol e tampão acetato $(50: 50 \mathrm{v} / \mathrm{v}) \mathrm{pH} 6,5$, com vazão de $1,0 \mathrm{~mL} / \mathrm{min}$. O tampão acetato foi preparado dissolvendose 7,708 g de acetato de amônia em $1000 \mathrm{~mL}$ de ácido acético glacial a $1 \%$ em água. $\mathrm{O}$ ajuste do $\mathrm{pH}$ da fase móvel foi realizado com uma solução de hidróxido de amônia $6 \mathrm{~N}$. O sistema cromatográfico foi operado à temperatura ambiente. A detecção foi realizada a 270 nm. Este comprimento de onda situa-se entre os máximos de absorção para a lamivudina e zidovudina (280 e 267 nm, respectivamente), determinados a partir das soluções das substâncias de referência e demonstrou um baixo nível sinal-ruído e uma boa especificidade ${ }^{1}$.

\section{Método}

\section{Preparação das amostras}

Foi determinado o peso médio de 20 comprimidos, os quais foram posteriormente pulverizados. Uma quantidade equivalente a 150 e $300 \mathrm{mg}$ de $3 \mathrm{TC}$ e AZT (peso médio), respectivamente, foi transferida para um balão volumétrico de $200 \mathrm{~mL}$, com auxílio de $100 \mathrm{~mL}$ de $\mathrm{HCl}$ 0,1 M, submetendo-se a amostra à agitação mecânica durante $20 \mathrm{~min}$, quando o volume do balão volumétrico foi completado com $\mathrm{HCl}$ 0,1 M. Após a centrifugação desta amostra, durante $10 \mathrm{~min}$, foi realizada uma diluição de $1,0 \mathrm{~mL}$ do sobrenadante em balão volumétrico de $25 \mathrm{~mL}$, completando-o com fase móvel. Esta solução foi filtrada através de membrana com $0,45 \mu \mathrm{m}$ de porosidade, obtendo-se uma concentração final de 30,0 e 60,0 $\mu \mathrm{g} / \mathrm{mL}$, para 3TC e AZT, respectivamente. A amostra A foi empregada no procedimento de validação do método, com exceção do teste de especificidade, que foi realizado com as 6 amostras empregadas, todas obtidas a partir de diferentes laboratórios farmacêuticos.

\section{Validação do método}

A validação do método foi realizada considerando-se as seguintes características: exatidão, precisão (repetibilidade e precisão intermediária), linearidade, faixa de concentração e especificidade $^{22,23}$.

\section{Linearidade}

A linearidade do método foi determinada pela realização da curva analítica. A partir da solubilização das respectivas substâncias de referência (3TC e AZT) na fase móvel, foram preparadas cinco soluções subseqüentes, em fase móvel, para cada substância (3TC: 24,0; 27,0; 30,0; 33,0 e 36,0 $\mu \mathrm{g} / \mathrm{mL}$; AZT: 48,0; 54,0; 60,0; 66,$0 ; 72,0 \mu \mathrm{g} / \mathrm{mL}$ ), dentro da faixa de $80-120 \%$ de uma concentração teórica de 30,0 e 60,0 $\mu \mathrm{g} / \mathrm{mL}$, para 3TC e AZT, respectivamen- te. A curva analítica foi preparada e analisada em triplicata (em dias diferentes). A linearidade foi estimada pela análise de regressão linear pelo método dos mínimos quadrados.

\section{$\underline{\text { Exatidão }}$}

A exatidão foi avaliada pelo teste de recuperação, analisandose, em triplicata, amostras de concentração conhecida (3TC: 24,43 $\mu \mathrm{g} / \mathrm{mL}$; AZT: 48,65 $\mu \mathrm{g} / \mathrm{mL}$ ) obtidas a partir de comprimidos do mesmo lote, adicionadas de três concentrações diferentes de substância de referência (3TC: 3,0; 6,0 e 9,0 $\mu \mathrm{g} / \mathrm{mL}$; AZT: 6,0; 12,0 e $18,0 \mu \mathrm{g} / \mathrm{mL}$ ). O percentual de recuperação (exatidão) foi calculado empregando-se a forma proposta pela $\mathrm{AOAC}^{24}$.

\section{$\underline{\text { Precisão }}$}

Para a determinação da repetibilidade foram analisadas em triplicata e no mesmo dia, amostras dos comprimidos em três concentrações diferentes (3TC: 27,0; 30,0 e 33,0 $\mu \mathrm{g} / \mathrm{mL}$; AZT: 54,0; 60,0 e $66,0 \mu \mathrm{g} / \mathrm{mL}$ ). Na determinação da precisão intermediária foram analisadas, em triplicata e em três dias diferentes, amostras dos comprimidos na mesma concentração (3TC: 30,0 $\mu \mathrm{g} / \mathrm{mL}$; AZT: $60,0 \mu \mathrm{g} / \mathrm{mL})$.

\section{Especificidade}

A especificidade do método foi avaliada através da comparação entre os cromatogramas obtidos a partir da solução padrão e das soluções amostra. As soluções amostra foram preparadas a partir de comprimidos provenientes de 6 diferentes laboratórios produtores.

\section{Avaliação da aplicabilidade do método nos testes de dissolução}

Para se avaliar a possibilidade de utilização do método cromatográfico descrito, após a sua validação foi realizado o teste de dissolução para 3 amostras diferentes de comprimidos, de acordo com os métodos oficiais descritos para medicamentos contendo lamivudina $^{21}$ ou zidovudina ${ }^{22}$. O teste de dissolução foi realizado utilizando como meio de dissolução $900 \mathrm{~mL}$ de água, a $37 \pm 0,5^{\circ} \mathrm{C}$ (Pharma Test, mod. PTWII, Hamburg, Alemanha). Após a imersão dos comprimidos, a agitação foi realizada utilizando o sistema de pás a $50 \mathrm{rpm}$, durante $30 \mathrm{~min}$. Após o tempo especificado (30 min), foram coletados $20,0 \mathrm{~mL}$ de cada cuba $(\mathrm{n}=6)$ e centrifugados. A partir dos sobrenadantes, foram realizadas diluições de $5 \mathrm{~mL}$ para balões volumétricos de $25 \mathrm{~mL}$, que foram completados com fase móvel. As amostras foram filtradas através de membrana com porosidade de $0,45 \mu \mathrm{m}$ e analisadas através de CLAE.

\section{RESULTADOS E DISCUSSÃO}

A inexistência de métodos oficiais para a quantificação da associação de lamivudina e zidovudina, em comprimidos, justifica o desenvolvimento e validação de métodos analíticos para esses fármacos, de maneira a auxiliar os laboratórios de controle de qualidade a garantir à população o acesso a medicamentos seguros e eficazes. Aliado a isso, o presente estudo foi desenvolvido buscando também a redução dos custos de análise e do impacto ambiental.

O método analítico para determinação das substâncias ativas (3TC e AZT) foi validado através de CLAE. A fase móvel constituída de metanol e tampão acetato (50:50 v/v) pH 6,5 mostrou-se adequada, proporcionando um tempo de análise de $5 \mathrm{~min}$, boa eficiência (pratos teóricos > 3000), com picos de boa resolução e simetria aceitável $(\mathrm{T}<2)^{22}$. As curvas analíticas apresentaram linearidade significativa ( $\mathrm{r}>0,999, \mathrm{p}<0,01$ ) na faixa de 24,0-36,0 e 48,0-72,0 $\mu \mathrm{g} / \mathrm{mL}$ para 3TC e AZT, respectivamente (Tabela 1).

A especificidade do método cromatográfico pôde ser determinada através da comparação entre os cromatogramas obtidos a partir da 
Tabela 1. Análise de regressão linear da curva analítica do padrão de lamivudina + zidovudina $(3 \mathrm{TC}+\mathrm{AZT})$

\begin{tabular}{lcc}
\hline Parâmetros & 3TC & AZT \\
\hline Faixa de concentração $(\mu \mathrm{g} / \mathrm{mL})^{*}$ & $24,0-36,0$ & $48,0-72,0$ \\
Equação da reta $(\mathrm{n}=3)$ & $\mathrm{y}=48524,57 \mathrm{x}$ & $\mathrm{y}=43451,03 \mathrm{x}$ \\
& +10382940 & +17722960 \\
Coeficiente de regressão & 0,9996 & 0,9996 \\
Coeficiente de determinação & 0,9993 & 0,9992 \\
Nível de significância & $\mathrm{p}<0,01$ & $\mathrm{p}<0,01$ \\
\hline
\end{tabular}

* 5 (cinco) concentrações do padrão, em triplicata.

solução padrão e das soluções amostra preparadas a partir dos comprimidos provenientes de diferentes laboratórios produtores $(n=6)$. A análise dos cromatogramas demonstrou a inexistência de quaisquer interferentes nos cromatogramas, independente da amostra analisada. Não foi observada interferência do solvente ou dos excipientes no comprimento de onda de detecção $(270 \mathrm{~nm})$, através da análise de amostras do placebo. A Figura 2 apresenta uma comparação entre o cromatograma obtido a partir da solução padrão e da solução amostra de um dos lotes de comprimidos utilizados (Amostra A).
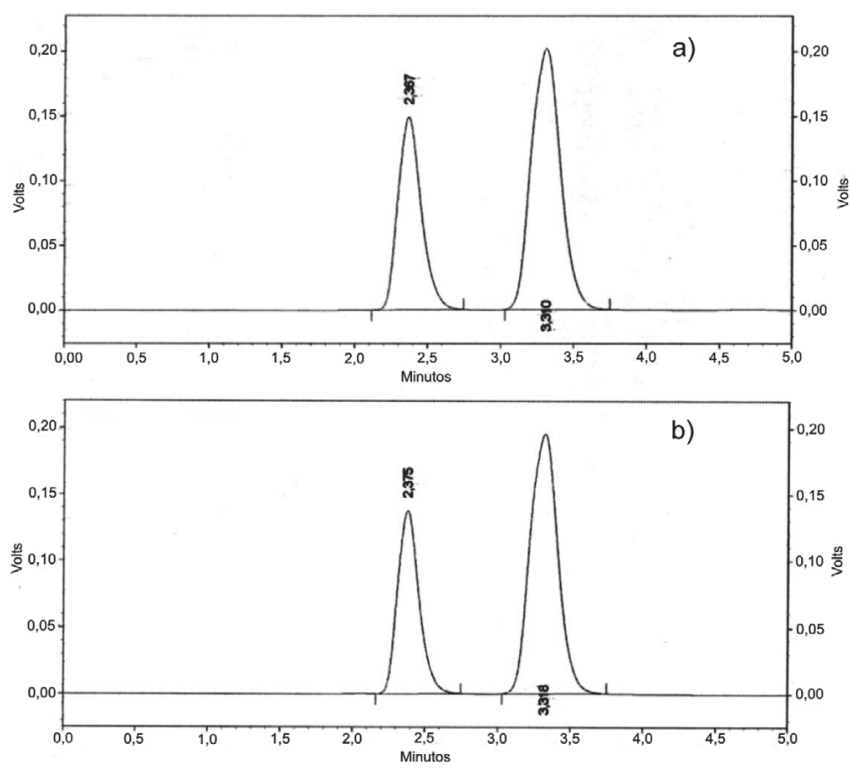

Figura 2. Cromatogramas obtidos para o padrão (a) e amostra (b) na validação do método cromatográfico para doseamento da lamivudina (3TC) e zidovudina (AZT). Condições: coluna: RP-18 (125 x $4 \mathrm{~mm}, 5$ um); fase móvel: metanol: tampão acetato (50:50) pH 6,5; vazão: $1 \mathrm{~mL} / \mathrm{min}$; detecção: $U V 270 \mathrm{~nm}$
Os resultados da avaliação da exatidão do método encontram-se na Tabela 2, demonstrando que o método apresenta uma exatidão adequada, com recuperação média das quantidades de substância adicionadas às amostras entre 95-105\% (3TC: 102,27\%; AZT: 102,40\%).

Tabela 2. Recuperação das soluções padrão de lamivudina (3TC) e de zidovudina (AZT) adicionadas às amostras e analisadas pelo método proposto $(\mathrm{n}=3)$

\begin{tabular}{|c|c|c|c|}
\hline \multirow[t]{2}{*}{ Fármaco } & \multicolumn{2}{|c|}{$\begin{array}{l}\text { Concentração da substância } \\
\text { de referência }(\mu \mathrm{g} / \mathrm{mL})\end{array}$} & \multirow[t]{2}{*}{ Recuperação (\%) } \\
\hline & Adicionada & Encontrada & \\
\hline \multirow[t]{4}{*}{$3 \mathrm{TC}$} & 3,00 & 3,09 & 103,01 \\
\hline & 6,00 & 6,14 & 102,31 \\
\hline & 9,00 & 9,13 & 101,49 \\
\hline & Média & & 102,27 \\
\hline \multirow[t]{4}{*}{ AZT } & 6,00 & 6,18 & 103,04 \\
\hline & 12,00 & 12,23 & 101,95 \\
\hline & 18,00 & 18,24 & 101,35 \\
\hline & Média & & 102,11 \\
\hline
\end{tabular}

Na Tabela 3 encontram-se os resultados obtidos para a precisão do método, incluindo a repetibilidade e precisão intermediária. Os coeficientes de variação encontrados na avaliação da repetibilidade apresentaram-se dentro da faixa de 0,11 e $0,68 \%$ (3TC: 0,11-0,68\%; AZT: 0,12-0,68\%). Na avaliação da precisão intermediária, os coeficientes de variação apresentaram-se em uma faixa de 0,10 e $1,75 \%$ (3TC: 0,10-1,75\%; AZT: 0,17-1,58\%). O conjunto destes resultados (repetibilidade e precisão intermediária) demonstra que o método analítico possui precisão satisfatória dentro da faixa de concentração avaliada.

Os resultados da validação do método demonstram a sua aplicabilidade nas análises de determinação do teor das substâncias ativas (3TC e AZT), em comprimidos. A partir disso, pode-se sugerir o emprego deste método nas análises de uniformidade de conteúdo, caracterizadas pela quantificação das substâncias ativas, em 10 comprimidos, individualmente. Neste caso, a amostra pode ser preparada pela adição de cada comprimido a balão volumétrico de $200 \mathrm{~mL}$, procedendo-se o mesmo protocolo de preparação da amostra descrito anteriormente. Esta hipótese foi testada para a amostra A, também empregada na validação do método, que apresentou teores para os 10 comprimidos testados entre 95,05 e $100,90 \%$ e 96,50 e $101,70 \%$, para 3TC e AZT, respectivamente.

A possibilidade de utilização deste método analítico para a quantificação das substâncias ativas nos testes de dissolução dos comprimidos também foi avaliada após a etapa de validação. A Tabela 4

Tabela 3. Avaliação da precisão (repetibilidade e precisão intermediária) do método cromatográfico para determinação da lamivudina 3TC e zidovudina - AZT $(n=3)$

\begin{tabular}{|c|c|c|c|c|c|c|}
\hline \multirow[b]{2}{*}{ Fármaco } & \multicolumn{3}{|c|}{ Repetibilidade } & \multicolumn{3}{|c|}{ Precisão Intermediária } \\
\hline & $\begin{array}{c}\text { Concentração } \\
(\mu \mathrm{g} / \mathrm{mL})\end{array}$ & $\mathrm{n}$ & $\begin{array}{c}\text { Coeficiente de } \\
\text { variação }(\%)\end{array}$ & Dia do ensaio & $\mathrm{n}$ & $\begin{array}{c}\text { Coeficiente de } \\
\text { variação }(\%)\end{array}$ \\
\hline \multirow[t]{4}{*}{$3 \mathrm{TC}$} & 24,00 & 3 & 0,68 & 1 & 3 & 0,10 \\
\hline & 30,00 & 3 & 0,15 & 2 & 3 & 1,75 \\
\hline & 36,00 & 3 & 0,11 & 3 & 3 & 0,75 \\
\hline & & & & $1+2+3$ & 9 & 1,30 \\
\hline \multirow[t]{4}{*}{ AZT } & 48,00 & 3 & 0,68 & 1 & 3 & 0,17 \\
\hline & 60,00 & 3 & 0,20 & 2 & 3 & 1,23 \\
\hline & 72,00 & 3 & 0,12 & 3 & 3 & 1,58 \\
\hline & & & & $1+2+3$ & 9 & 1,87 \\
\hline
\end{tabular}


apresenta os dados obtidos no teste de dissolução de diferentes amostras (amostras A, B e C). Todas as amostras apresentaram um percentual médio dissolvido maior que $90 \%$. A análise dos cromatogramas obtidos a partir das diferentes amostras coletadas do meio de dissolução não demonstrou a existência de interferentes nos cromatogramas.

Tabela 4. Percentuais dissolvidos (\%) após $30 \mathrm{~min}$ no teste de dissolução dos comprimidos de lamivudina - 3TC e zidovudina AZT $(150+300 \mathrm{mg})$

\begin{tabular}{lcc}
\hline Amostra & Fármaco & $\begin{array}{c}\% \text { dissolvido } \\
\text { Média } \pm \mathrm{dp}(\mathrm{n}=6)\end{array}$ \\
\hline A & 3 TC & $101,24 \pm 3,00$ \\
& AZT & $104,46 \pm 2,90$ \\
B & 3 TC & $95,82 \pm 13,85$ \\
& AZT & $97,51 \pm 13,69$ \\
C & 3 TC & $98,48 \pm 6,62$ \\
& AZT & $98,97 \pm 6,16$ \\
\hline
\end{tabular}

\section{CONCLUSÕES}

A validação do método de análise por cromatografia líquida de alta eficiência da lamivudina e zidovudina em comprimidos demonstrou que este é preciso, exato, específico e linear. A partir disso, representa uma alternativa para a quantificação destas substâncias ativas no testes de determinação do teor e uniformidade de conteúdo de comprimidos e teste de dissolução. O método desenvolvido é caracterizado pela utilização reduzida de solvente orgânico na etapa de preparação da amostra, em relação a outros métodos relatados na literatura, proporcionando maior economia e menor impacto ambiental.

\section{REFERÊNCIAS}

1. Verweij-Van Wissenab, C. P. W. G. M.; Aarnoutse, R. E.; Burger, D. M.; J. Chromatogr. B.: Anal. Technol. Biomed. Life Sci. 2005, 816, 121.

2. Bezy, V.; Morin, P.; Couerbe, P.; Leleu, G.; Agrofoglio, L.; J. Chromatogr B.: Anal. Technol. Biomed. Life Sci. 2005, 821, 132.

3. Kamali, F.; Clin. Invest. Med. 1993, 71, 392.

4. Perry, C. M.; Faulds, D.; Drugs 1997, 53, 657.

5. Uslu, B.; Özkan, S. A.; Anal. Chim. Acta 2002, 466, 175.

6. Baig, M. V.; Gapse, G. S.; Raju, S. A.; Asian J. Chem. 2001, 13, 185

7. Erk, N.; Pharmazie 2004, 59, 106.

8. Alnouti, Y.; White, C. A.; Bartlett, M. G.; Biomed. Chromatogr. 2004, 18, 641.

9. Aymard, G.; Legrand, M.; Trichereau, N.; Diquet, B.; J. Chromatogr. B.: Anal. Technol. Biomed. Life Sci. 2000, 744, 227.

10. Kenney, K. B.; Wring, S. A.; Carr, R. M.; Wells, G. N.; Dunn, J. A.; J. Pharm. Biomed. Anal. 2000, 22, 967.

11. Pereira, A. S.; Kenney, K. B.; Cohen, M. S.; Hall, J. E.; Eron, J. J.; Tidwell, R. R.; Dunn; J. A.; J. Chromatogr. B.: Anal. Technol. Biomed. Life Sci. 2000, 742, 173

12. Anbazhagan, S.; Indumathy, N.; Shanmugapandiyan, N.; Sridhar, S. K.; J. Pharm. Biomed. Anal. 2005, 39, 801.

13. Djurdjevic, P.; Laban, A.; Markovic, S.; Jelikic-Stankov, A.; Anal. Lett. 2004, 37, 2649.

14. Dunge, A.; Sharda, N.; Singh, B.; Singh, S.; J. Pharm. Biomed. Anal. 2005, 37,1109 .

15. Fernandes, C.; de Campos, L. M. M.; Pianetti, G. A.; Rev. Bras. Cien. Farm. 2003, 39, 381

16. Ozkan, A. S.; Uslu, B.; J. Liq. Chromatogr. Relat. Technol. 2002, 25, 1447.

17. Basavaiah, K.; Somashekar, B. C.; J. Sci. Ind. Res. India 2006, 65, 349.

18. Kapoor, N.; Khandavilli, S.; Panchagnula, R.; J. Pharm. Biomed. Anal. 2006, 41,761

19. Santoro, M. I. R. M.; Taborianski, A. M.; Singh, A. K.; Kedor-Hackmann, E. R. M.; Quim. Nova 2006, 29, 240.

20. da Silva, G. R.; Lages, G. P.; Pianetti, G. A.; Nunan, E. de A.; Soares, C. D. V.; de Campos, L. M. M.; Quim. Nova 2006, 29, 1159.

21. Farmacopéia Brasileira; IV ed., Atheneu: São Paulo, 2003, fascículo 4.

22. United States Pharmacopeia; 29 ed., The United States: Rockville Pharmacopeial Convention, 2005.

23. ICH-Harmonised Tripartity Guideline; Validation of Analytical Procedures: Methodology. IFPMA: Geneva, 1996.

24. AOAC, Association of Analytical Chemists; Official Methods of Analysis, $15^{\text {th }}$ ed., AOAC: Arlington, 1990. 